\title{
Radiofrequency ablation of benign thyroid nodules: evaluation of the treatment efficacy using ultrasonography
}

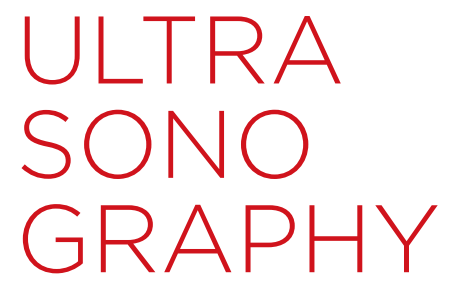

\author{
Hye Shin Ahn', Soo Jin Kim², Sung Hee Park', Mirinae Seo ${ }^{1}$ \\ 'Department of Radiology, Chung-Ang University Hospital, Seoul; '2Department of Radiology, \\ New Korea Hospital/Human Medical Imaging and Intervention Center, Gimpo, Korea
}

\section{ORIGINAL ARTICLE}

http://dx.doi.org/10.14366/usg. 15083 pISSN: 2288-5919 - elSSN: 2288-5943 Ultrasonography 2016;35:244-252

Purpose: The aim of this study was to evaluate the efficacy of radiofrequency (RF) ablation for benign thyroid nodules and assess the usefulness of internal factors (ultrasonographic findings) and external factors (treatment-related findings) in prediction of treatment efficacy.

Methods: We evaluated 22 benign thyroid nodules from 19 patients treated with RF ablation between March 2010 and January 2013. The internal and external factors of these nodules were retrospectively reviewed and correlated with the therapeutic success and the volume reduction ratio (VRR). The volume and size of the nodules were determined before treatment, and the VRR was calculated at 6 -month and 1-year follow-up examinations after RF ablation. Therapeutic success was defined as a $>50 \%$ volume reduction.

Results: The mean VRRs were $66.1 \pm 18.7 \%$ at 6 months and $74.3 \pm 16.7 \%$ at 1 year. The therapeutic success rate after 6 months and 1 year was $81.8 \%$ and $90.9 \%$, respectively. At the 1 -year follow-up, the margin of the nodule correlated with therapeutic success. Most of the successfully ablated nodules showed well-defined margins on initial ultrasonography (18/20, $90 \%)(P=0.026)$. In addition, nodules with ill-defined margins showed a tendency toward having a low VRR at the 6-month and 1-year follow-up examinations.

Conclusion: RF ablation was effective in decreasing the volume of benign thyroid nodules. Thyroid nodules with well-defined margins tended to show successful outcomes at the 1-year follow-up examination after RF ablation.

Keywords: Thyroid nodule; Ablation techniques; Ultrasonography

\section{Introduction}

Radiofrequency (RF) ablation is a minimally invasive technique that has been frequently used to treat hepatic malignancy [1-3]. It may serve as an alternative to surgery for the management of benign thyroid nodules that cause symptoms and cosmetic problems, and many studies have reported the efficacy and safety of RF ablation in such cases [4-13]. Kim et al. [4] reported the initial findings obtained with RF ablation for benign thyroid nodules, and showed that the volume reduction ratio (VRR) at the last follow-up (range, 9 to 18.5 months) was $88 \%$. Mid- to long-term follow-up results have also been reported recently. Spiezia et al. [10] demonstrated a VRR of $79.4 \%$ at 2 years after RF

Received: December 28, 2015

Revised: March 22, 2016

Accepted: March 23, 2016

Correspondence to:

Soo Jin Kim, MD, Department of Radiology, New Korea Hospital, 283 Gimpo hangang 3-ro, Gimpo 10086, Korea

Tel. +82-31-980-9126

Fax. +82-31-982-9800

E-mail: ksj1567@hanmail.net

This is an Open Access article distributed under the terms of the Creative Commons Attribution NonCommercial License (http://creativecommons.org/ licenses/by-nc/3.0//) which permits unrestricted noncommercial use, distribution, and reproduction in any medium, provided the original work is properly cited.

Copyright (C) 2016 Korean Society of Ultrasound in Medicine (KSUM)

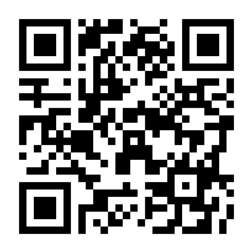

How to cite this article:

Ahn HS, Kim SJ, Park SH, Seo M. Radiofrequency ablation of benign thyroid nodules: evaluation of the treatment efficacy using ultrasound. Ultrasonography. 2016 Jul;35(3):244-252. 
ablation, and Lim et al. [11] found a VRR of $93.5 \%$ at 49 months after the procedure. Many other studies have determined the improvement in patients' symptomatic and cosmetic scores after RF ablation and reported low complication rates after the procedure $[4-11,14,15]$.

Although RF ablation has been used for the successful management of benign thyroid nodules, there have been, to our knowledge, few studies on the factors that affect the results of RF ablation. Jeong et al. [5] found that mainly cystic nodules decreased rapidly in volume at 1 and 3 months after RF ablation; therefore, the composition of the nodule might be correlated with treatment response. In another recent study, the authors demonstrated that the initial volume and solidity of the nodule were independent predictive factors for the efficacy of RF ablation [11]. While there have been a few studies reporting variations in ultrasonographic findings that could potentially predict the treatment efficacy of RF ablation, there have thus far been no proven predictors on ultrasonography (US) reported in the literature.

Therefore, we aimed to assess the efficacy of RF ablation for benign thyroid nodules and evaluate the usefulness of internal factors (ultrasonographic findings) and external factors (treatmentrelated findings) in predicting treatment efficacy.

\section{Materials and Methods}

\section{Patients}

This retrospective study received the appropriate Institutional Review Board approval from our institution. Informed consent was obtained from all patients undergoing US-guided fine-needle aspiration biopsy (FNAB) and RF ablation. Between March 2010 and January 2013, 34 benign thyroid nodules in 29 euthyroid patients treated with US-guided RF ablation were consecutively enrolled. Inclusion criteria of the study were as follows: presence of cosmetic or symptomatic problems; benign cytological results in two separate US-guided FNAB procedures [16,17]; US imaging findings without malignant suspicious features; and refusal to undergo surgery or poor surgical compliance [15].

Out of the original sample, 22 nodules were finally included in this study, from 19 patients (1 man, 18 women) who participated in a follow-up period of more than 1 year. The mean patient age was 44.5 years (range, 27 to 78 years). There were 16 cases of nodular hyperplasia, five cases involving benign follicular nodules, and one case of lymphocytic thyroiditis. Laboratory studies, including a thyroid function test (thyroid-stimulating hormone, triiodothyroxine, free thyroxine), complete blood count, and a blood coagulation test (prothrombin time, activated partial thromboplastin time) were performed and the values were within normal range in all patients.

\section{US and US-Guided RF Ablation}

Real-time thyroid US was performed by one of two radiologists with 8 years of thyroid imaging experience, respectively; the procedure was performed using high-resolution (12- or $17-\mathrm{MHz}$ electronically focused linear-array transducer) US equipment (IU 22, Philips Ultrasound, Bothell, WA, USA). Three orthogonal diameters of the nodules (the largest diameter and two other perpendicular diameters) were measured by US before the procedure. The volume of the nodules was calculated using the following equation: $V=\pi a b c / 6$ (where $V$ is the volume; $a$, the largest diameter, and $b$ and $c$, the other two perpendicular diameters) [5]. The vascularity of the nodules on color Doppler images was visually assessed by an examiner, and was classified as internal vascularity, marginal vascularity, or no vascularity.

US-guided RF ablation was performed by the same radiologist who performed the US assessment. The radiologist determined the approach route for the electrode under US guidance. The procedure was performed with a RF generator (Cool-tip RF systems, Radionics, Valleylab, Boulder, CO, USA) and 18-gauge, 1- or 0.7-cm active tip, internally cooled electrodes (Covidien, Taewoong Medical, Gimpo, Korea). For local anesthesia, the patients were treated with $2 \%$ lidocaine at the puncture site. We used the trans-isthmic approach and moving shot technique under US guidance $[5,8,15,18]$. To prevent complications during the procedure, we carefully observed the adjacent structures, including nerves and vessels [19]. Ablation was performed with 30-50 W of RF power. An electrode was inserted into the nodule using the trans-isthmic approach. Initially, the electrode tip was positioned in the deepest and farthest area of the nodule, and a transient hyperechoic zone appeared at the periphery of the nodule within 5-10 seconds of turning on the $\mathrm{RF}$ power. If the patient complained of pain during the procedure, the RF power was reduced or turned off for several seconds. The procedure was terminated when the entire visualized area of the nodule had become a transient hyperechoic zone. Complications during and after the RF ablation procedure were checked according to the clinical symptoms and US findings (pain/voice change/ hematoma/skin burn/nodule rupture) $[14,15]$.

\section{Analysis of Factors That Affect the Treatment Result}

In the initial pre-ablation US assessment, we evaluated the ultrasonographic findings of the nodule, including the site, composition, echogenicity, margin, shape, calcification, and vascularity of the nodule by reference to a previous multi-center study [20]. Image analyses were performed in consensus by two radiologists with 2 and 8 years of thyroid imaging experience. We also assessed the patient's age and the initial size (largest diameter) and volume of the nodule. At 6-month and 1-year intervals after RF ablation, 
follow-up US examinations were performed along with clinical examinations. Changes in the size and the volume reduction rate of the nodules were described and the VRR was determined. The VRR was calculated as follows: VRR $(\%)=[$ (Initial volume-Final volume $\times 100] /$ Initial volume. Therapeutic success rate was defined as a $>50 \%$ volume reduction at each follow-up US examination $[11,15]$. Recurrence and/or regrowth of the nodule was defined as a $>50 \%$ volume increase compared with the findings of previous US examinations [11,21].

We also evaluated treatment-related findings including the delivery energy, running time, number of sessions, and complications related with the procedure. Treatment-related US findings such as the presence of an undertreated area and post-procedural vascularity of the nodule were also determined immediately after the ablation and during the follow-up examinations.

\section{Statistical Analysis}

All statistical analyses were performed using commercially available software SPSS ver. 21.0 (IBM Co., Armonk, NY, USA). Paired t tests were used to compare the size and volume of the nodule before RF ablation and at the 6-month and 1-year follow-up examinations. We compared factors that could affect the treatment result between the therapeutic success group and the non-success group. The MannWhitney test was used for continuous variables (initial volume and size of the nodule, patient's age, delivery energy, and running time) and Fisher exact test was used for other categorical data, including the internal factors related to the nodule and the external factors related to RF ablation. We also correlated the above factors with the VRR at 6 months and 1 year using a two-sample t test. A value of $\mathrm{P}<0.05$ was considered to indicate statistical significance.

\section{Results}

Most of the patients $(17 / 19,89.5 \%)$ received RF ablation for one nodule, and the other two patients received treatment for two and three nodules. Among the 22 treated nodules, 12 nodules were

Table 1. Changes in the volume and size of the thyroid nodules and VRR

\begin{tabular}{lccc}
\hline \multicolumn{1}{c}{ Variable } & Initial & 6 Months & 1 Year \\
\hline Number & 22 & 22 & 22 \\
Size $(\mathrm{cm})$ & $3.9 \pm 1.1$ & $2.6 \pm 0.9$ & $2.3 \pm 0.8$ \\
Volume $(\mathrm{mL})$ & $14.3 \pm 13.4$ & $4.7 \pm 6.3$ & $3.6 \pm 4.8$ \\
VRR $(\%)$ & & $66.1 \pm 18.7$ & $74.3 \pm 16.7$ \\
& & $(17.3-89.9)$ & $(25.0-92.8)$ \\
\hline
\end{tabular}

Values are presented as number or mean \pm SD (range).

VRR, volume reduction ratio. treated in one session of RF ablation (12/22, 54.5\%), and the other 10 nodules required more than one session ( 2 sessions, $n=9 ; 3$ sessions, $n=1$ ). In the cases involving multiple treatment sessions, the second session was performed between 1 to 3 months after the initial procedure and the third session was performed 6 months after the initial session. There were no cases of recurrence or regrowth of the nodules.

\section{Change in the Volume and Size of the Thyroid Nodule and VRR}

Among the included patients, nine patients achieved a 2-year follow-up and the mean follow-up period was $3.6 \pm 4.8$ months (range, 12 to 24 months) in all patients. The size and volume of the thyroid nodules significantly decreased from the initial US findings (Table 1). The size decreased from $3.9 \pm 1.1 \mathrm{~cm}$ before ablation to $2.6 \pm 0.9 \mathrm{~cm}$ and $2.3 \pm 0.8 \mathrm{~cm}$ at the 6-month and 1-year followup examinations, respectively $(n=22, P<0.001)$. The volume also decreased significantly from $14.3 \pm 13.4 \mathrm{~mL}$ before ablation to $4.7 \pm 6.3 \mathrm{~mL}$ and $3.6 \pm 4.8 \mathrm{~mL}$ at the 6 -month and 1-year followup examinations, respectively $(n=22, P<0.001)$. The nine patients with a 2-year follow-up examination showed a marked decrease in volume $(3.3 \pm 2.6 \mathrm{~mL})$ and size $(2.2 \pm 0.7 \mathrm{~cm})$ of the nodules. The mean VRRs at 6 months and 1 year were $66.1 \pm 18.7 \%$ (range, $17.3 \%$ to $89.9 \%$ ) and $74.3 \pm 16.7 \%$ (range, $25.0 \%$ to $92.8 \%$ ), respectively. The therapeutic success rate was $81.8 \%(18 / 22)$ at 6 months and $90.9 \%(20 / 22)$ at 1 year after ablation (Fig. 1).

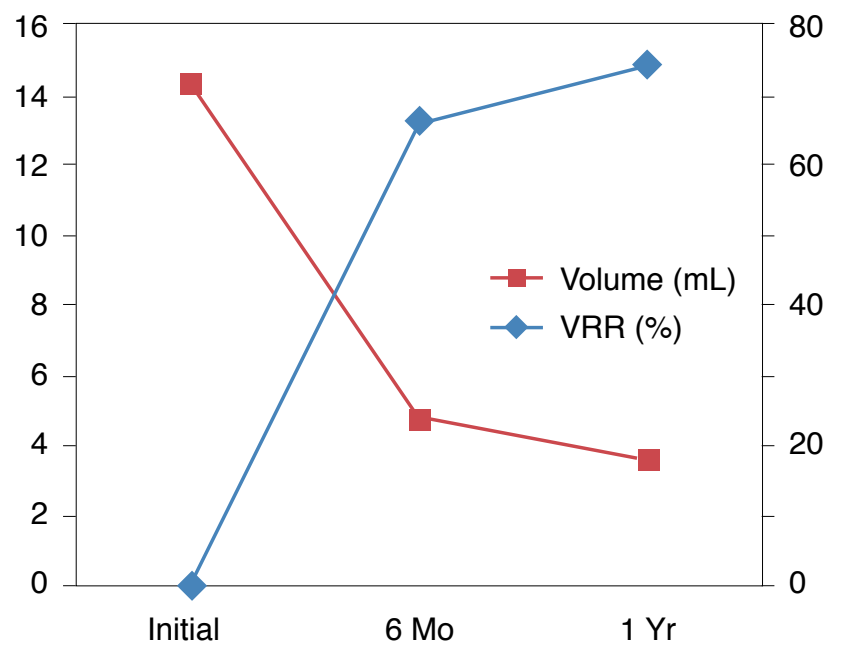

Fig. 1. Changes in the volume of the thyroid nodules and volume reduction ratio (VRR). Graph shows that the mean volume of benign thyroid nodules is markedly decreased after radiofrequency ablation on the 6-month and 1-year follow-up ultrasonography. 


\section{Analysis of Factors That Affect the Treatment Result}

Among the internal factors, only the nodule margin was correlated with therapeutic success at 1 year after ablation $(P=0.026)$ (Table 2). Most of the successfully ablated nodules showed well-defined margins on initial US examination (18/20,90\%). In addition, the nodules with ill-defined margins showed a tendency of low VRR at the 6-month follow-up (mean, $0.5 \pm 0.3$ vs. $0.7 \pm 0.1$ ) and the 1-year follow-up (mean, $0.6 \pm 0.3$ vs. $0.8 \pm 0.1$ ), but there was no statistical significance ( $P=0.443$ in 6-month and $P=0.366$ in 1-year). Other internal factors were not significantly correlated with VRR $(P>0.05)$. Among external factors, the presence of an undertreated area, post-procedural vascularity of the nodule after treatment, and the number of sessions were significantly correlated with therapeutic success at 6 months after ablation. However, none of these factors showed a significant correlation with therapeutic success at 1 year after ablation (Table 3). At the 6-month follow-up, VRR was

Table 2. Comparison of internal findings of the nodule according to therapeutic success

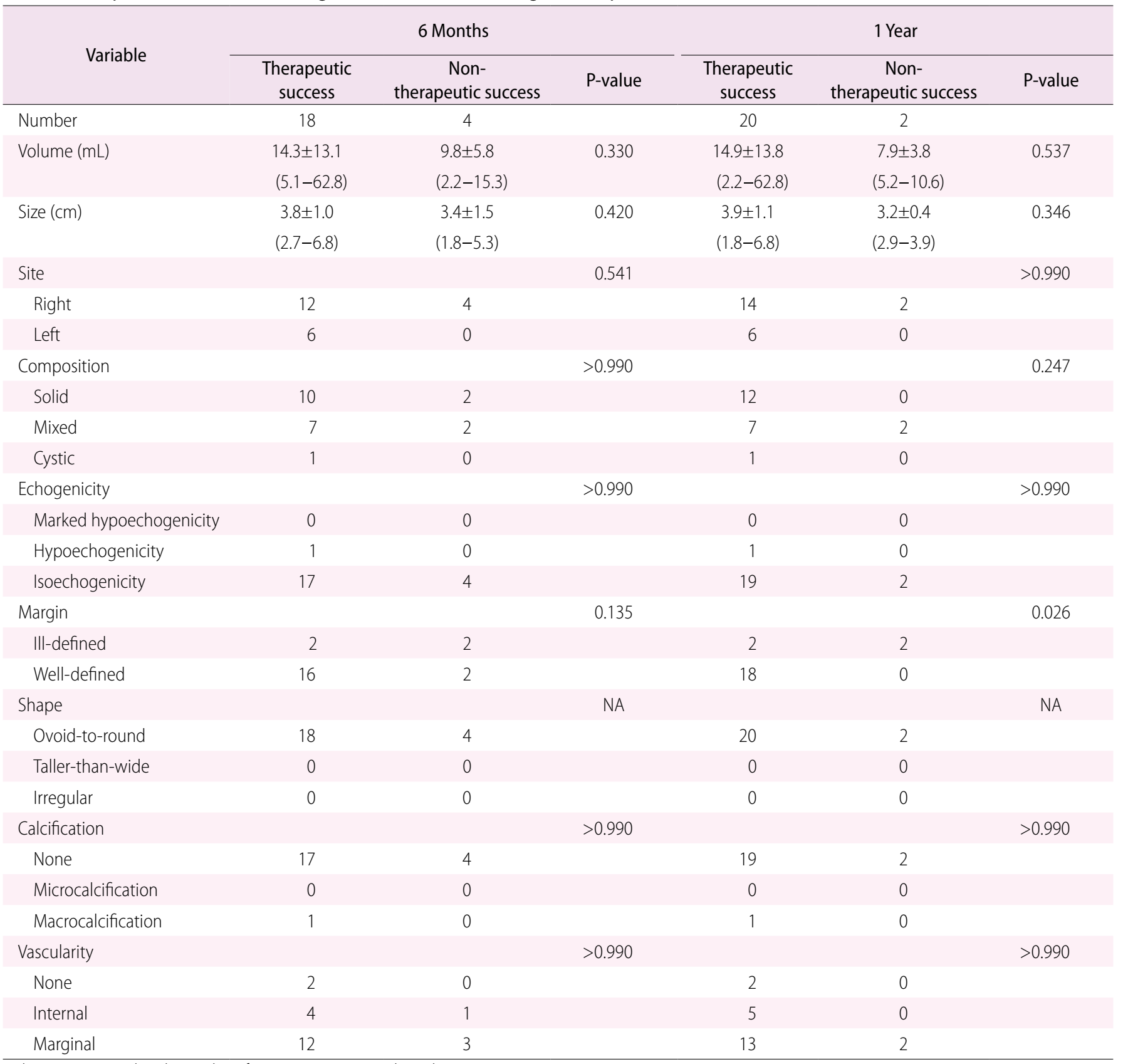

Values are presented as the number of patients or mean \pm SD (range).

NA, not applicable. 
relatively lower in nodules with an undertreated area (mean, $0.5 \pm 0.2$ vs. $0.74 \pm 0.10 ; P=0.05$ ) or with post-procedural vascularity (mean, $0.6 \pm 0.2$ vs. $0.7 \pm 0.1 ; P=0.068$ ), or with multiple sessions (mean, $0.6 \pm 0.2$ vs. $0.7 \pm 0.1 ; P=0.122$ ). At the 1-year follow-up, these factors still showed a tendency to have a low VRR; however there was no statistical significance due to the decreased gap in VRR within each factor $(P>0.05)$. Other internal factors were not significantly correlated with VRR $(P>0.05)$.

\section{Complications}

We assessed the clinical symptoms and the US findings during RF ablation, including severe pain, voice changes, hematoma, skin burns, and nodule rupture. There were no minor and major complications in the patients included in the study. During RF ablation, most of the patients complained of mild local pain and a tolerable heating sensation in the neck. All of these patients improved without sequelae. No patient experienced life-threatening or delayed complications during the follow-up period.

\section{Discussion}

Thyroid nodules are very common and may be observed with US in $50 \%$ of the adult population; however, less than $7 \%$ of thyroid nodules are malignant [22]. Most thyroid nodules are benign, but some symptomatic nodules require treatment. Surgical excision and levothyroxine medication are the traditional treatment procedures for benign thyroid nodules; however, non-surgical, minimally invasive techniques have been proposed to solve many of the drawbacks of surgery and medication $[4,5,8,10]$. Non-surgical treatments such as ethanol ablation, laser ablation, and RF ablation have been reported over the last 20 years. Among these methods, RF ablation is the most recently proposed alternative treatment for solid thyroid nodules. RF ablation is effective in reducing nodule volume by $33 \%-$ $58 \%$ at 1 month and $51 \%-92 \%$ at 6 months after the procedure [4-10]. Lim et al. [11] described a VRR of $93.5 \%$ at 49 months after the procedure, which was the longest follow-up duration ever reported for this procedure. RF ablation has been used to treat benign thyroid nodules and has yielded good results compared with surgery. Bemardi et al. [23] compared the efficacy, tolerability, and costs of RF ablation with those of surgery. Their findings showed that RF ablation was sufficiently effective for treating nodulerelated clinical problems, although surgery was more effective for treating huge nodules and autonomously functioning nodules. One of the strengths of the surgical approach is that it allows a final pathologic diagnosis. The authors found that the majority of the unrevealed thyroid carcinomas during two fine-needle aspiration

Table 3. Comparison of RF ablation related findings according to therapeutic success

\begin{tabular}{|c|c|c|c|c|c|c|}
\hline \multirow{2}{*}{ Variable } & \multicolumn{3}{|c|}{6 Months } & \multicolumn{3}{|c|}{1 Year } \\
\hline & $\begin{array}{c}\text { Therapeutic } \\
\text { success }\end{array}$ & $\begin{array}{c}\text { Non- } \\
\text { therapeutic success }\end{array}$ & P-value & $\begin{array}{c}\text { Therapeutic } \\
\text { success }\end{array}$ & $\begin{array}{c}\text { Non- } \\
\text { therapeutic success }\end{array}$ & P-value \\
\hline Number & 18 & 4 & & 20 & 2 & \\
\hline Age (yr) & $45.0 \pm 14.5$ & $44.1 \pm 13.0$ & 0.310 & $44.5 \pm 13.9$ & $60.0 \pm 0.0$ & 0.082 \\
\hline Delivery energy (kcal) & $3.7 \pm 4.9$ & $1.9 \pm 0.8$ & 0.386 & $3.7 \pm 4.7$ & $1.5 \pm 0.0$ & 0.485 \\
\hline Running time (sec) & $509.7 \pm 398.7$ & $345.0 \pm 57.5$ & 0.859 & $500.1 \pm 382.1$ & $420.0 \pm 0.0$ & 0.563 \\
\hline Number of session & $1.5 \pm 0.6$ & $2.0 \pm 0.0$ & 0.029 & $1.5 \pm 0.6$ & $2.0 \pm 0.0$ & 0.247 \\
\hline 1 & 12 & 0 & & 12 & 0 & \\
\hline 2 & 5 & 4 & & 7 & 2 & \\
\hline 3 & 1 & 0 & & 1 & 0 & \\
\hline Undertreated area & & & 0.010 & & & 0.121 \\
\hline Present & 4 & 4 & & 6 & 2 & \\
\hline Absent & 14 & 0 & & 14 & 0 & \\
\hline Post-procedural vascularity & & & 0.029 & & & 0.195 \\
\hline Present & 6 & 4 & & 8 & 2 & \\
\hline Absent & 12 & 0 & & 12 & 0 & \\
\hline Radiologist & & & 0.115 & & & 0.494 \\
\hline S.H.P. & 9 & 4 & & 11 & 2 & \\
\hline S.J.K. & 9 & 0 & & 9 & 0 & \\
\hline
\end{tabular}

Data are indicated as the number of patients or mean $\pm S D$. 
procedures prior to the RF ablation were microcarcinomas (5/6, $83 \%)$. Moreover, in recent studies, RF ablation showed high efficacy and safety in patients with bilateral benign thyroid nodules or autonomously functioning thyroid nodules $[12,13]$.

In our study, the mean VRR was $66.1 \%$ and $74.3 \%$ at the 6-month and 1-year follow-up, respectively. The results of our study showed that RF ablation induced significant reduction in nodule volume compared with previous studies [4-11]. We evaluated both the internal factors (ultrasonographic findings) and the external factors (treatment-related findings). We found that the treatment efficacy of RF ablation was affected by three external factors at 6 months and the margin of the nodule at 1 year after the procedure. The presence of an undertreated area, the postprocedural vascularity of the nodule, and the number of sessions were correlated with therapeutic success at the 6-month followup, but these factors showed no statistical significance in the therapeutic success and the VRR at 1 year after the procedure. Therefore, we determined that these external factors that depended on the clinicians were not actual predictive factors. Several studies have found that initial volume and initial solidity of the nodule were strong predictors of treatment response $[5,8,11]$. In this study, however, the margin of the nodule was the sole significant predictor of therapeutic success at the 1-year follow-up. There were four ill-defined nodules in our study and therapeutic success could not be achieved in two of them at the 1-year follow-up. These two nodules were found in one patient who received multi-session RF ablation for two conglomerated nodules and another single nodule. Treatment for the two conglomerated nodules was not successful

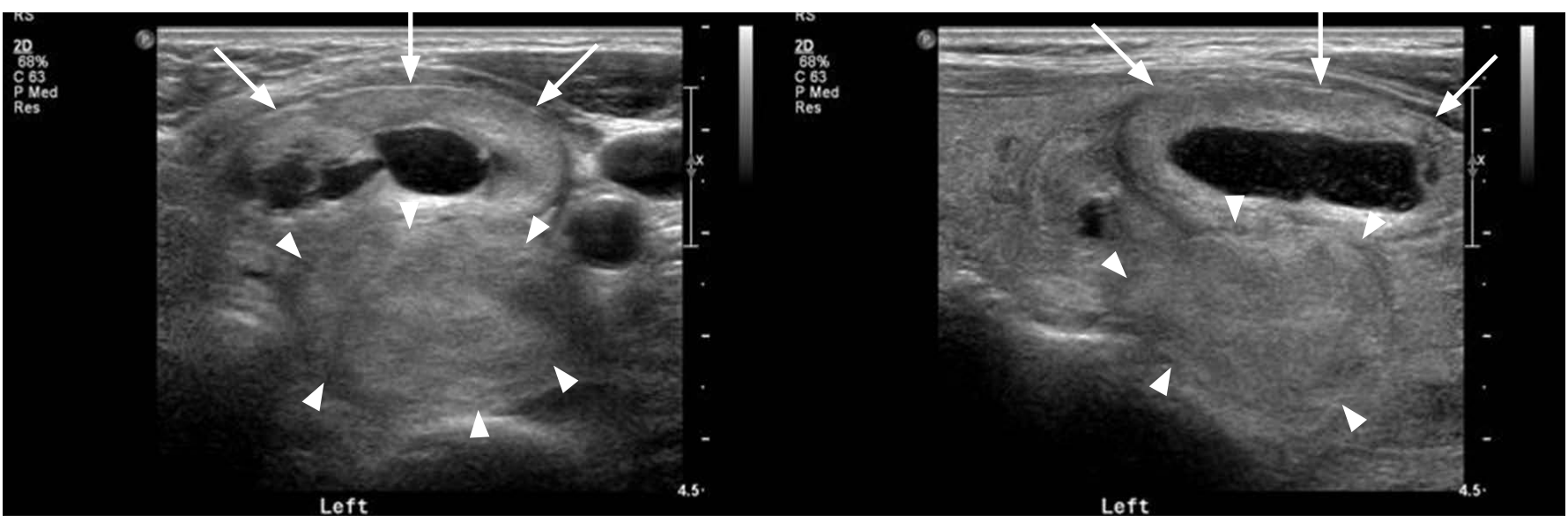

A

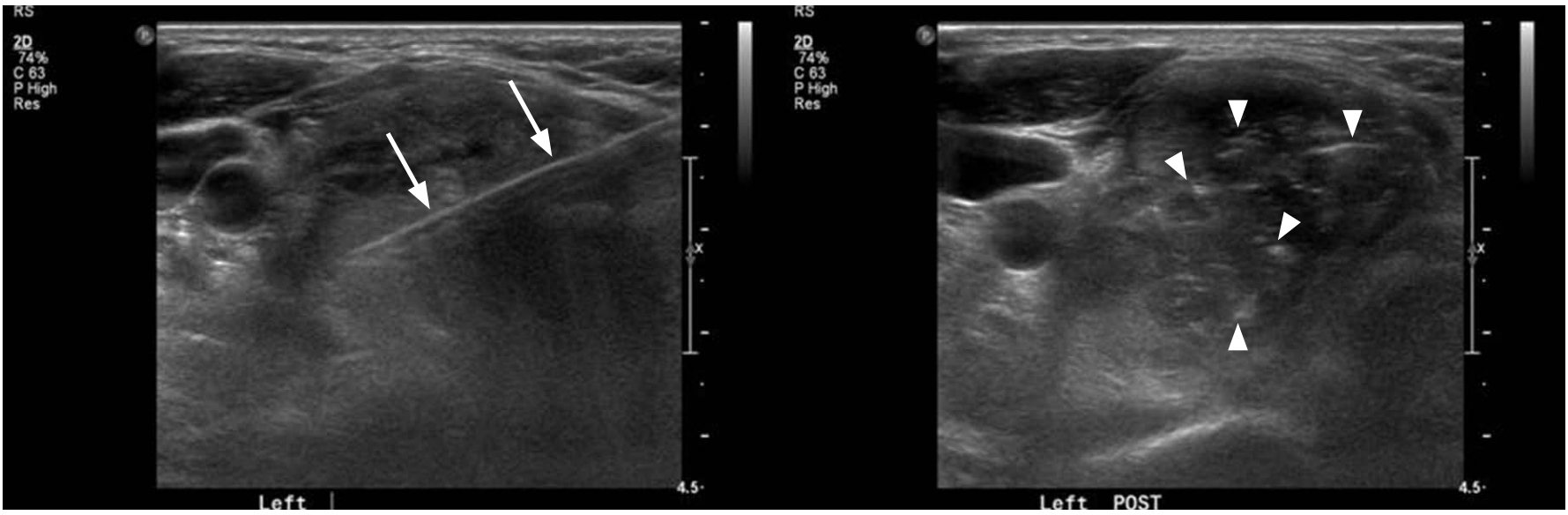

B

Fig. 2. A 60-year-old woman with two conglomerated solid nodules in the left thyroid.

A. Initial ultrasonogram shows a predominantly solid nodule (arrows) in the superficial area and a pure solid nodule (arrowheads) in the deep portion of the left thyroid abutting each other, with the deep nodule showing a relatively ill-defined margin in the lateral and posterior aspects in comparison with the superficial nodule. B. During the radiofrequency ablation, an internally cooled electrode (arrows) is inserted into the nodules and multiple echogenic micro-bubbles (arrowheads) were noted within the nodules after the procedure. 


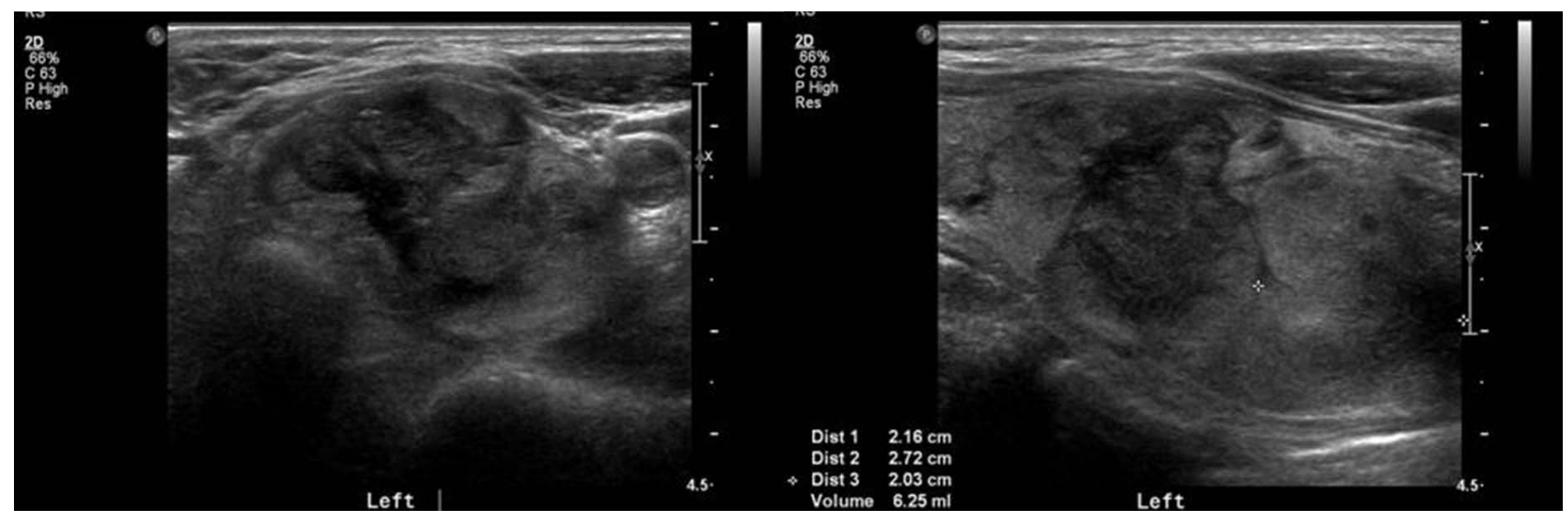

C

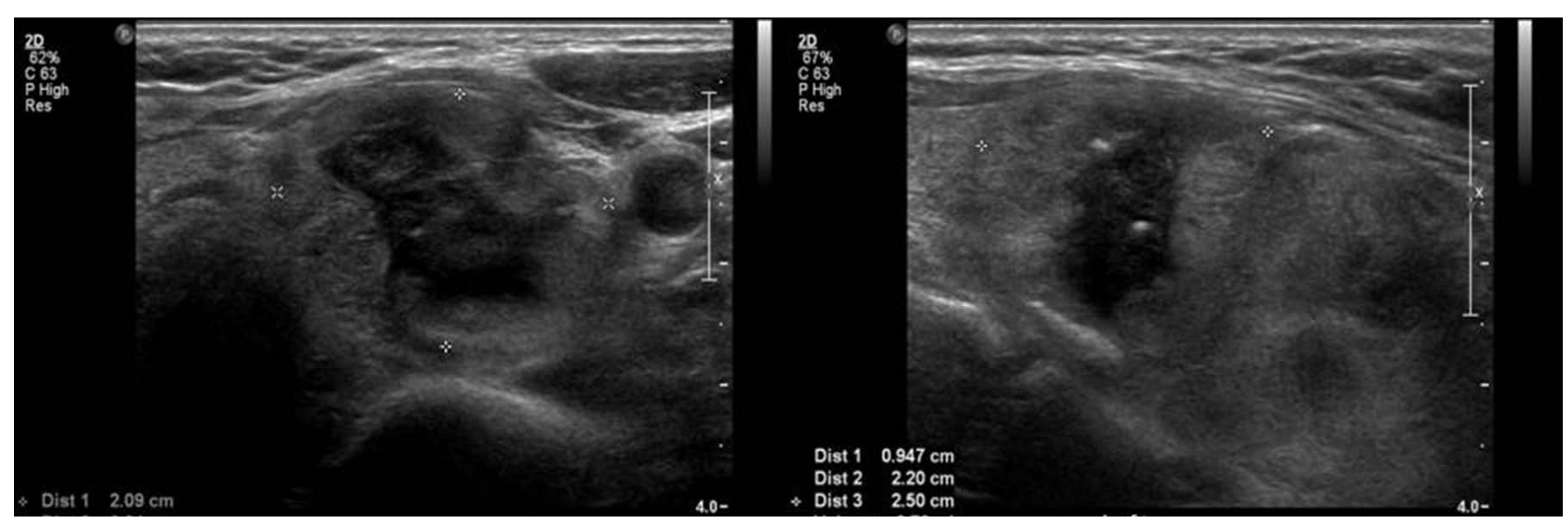

D

Fig. 2. C. On 1-month follow-up ultrasonography after the ablation, the nodules are slightly decreased in volume and size, with the volume reduction ratio of the superficial nodule being $36 \%$ and that of the deep nodule being $23 \%$; thus a second session of radiofrequency ablation was performed for these nodules. D. On 1-year follow-up ultrasonography after the ablation, superficial and deep nodules show a greater decrease in volume ( $43 \%$ and $25 \%$, respectively), but they do not achieve a volume reduction ratio of more than $50 \%$; thus the therapeutic success criteria are not satisfied in this patient.

(Fig. 2). In this study, we defined a part of the poorly demarcated margin in which the tumor cannot be discriminated from the normal parenchyma as an ill-defined margin [20]. Moreover, to minimize the marginal recurrence, we used the moving-shot technique to improve the efficacy of thyroid RF ablation [24]. Therefore, we hypothesized that an ill-defined margin would be predictive of treatment failure due to incomplete ablation caused by a poor demarcation between the nodule and normal tissue. On the other hand, a well-defined margin allows complete ablation around the boundary of the nodule, increasing the likelihood of successful treatment. Baek et al. [25] have reported the factors that may reduce the efficacy of RF ablation. The tissue temperature during the procedure, the heterogeneity, and the blood flow in the target nodule must be carefully considered to ensure therapeutic success. In a recent study, Gambelunghe et al. [26] demonstrated that the effectiveness of laser ablation can be predicted by nodule morphology. Welldefined nodules tended to show a better response to treatment in comparison with conglomerated nodules at 12 months after laser ablation. The authors hypothesized that the increased vascularity of nodular conglomerates, which could favor the dispersion of the heat supplied with the laser fiber, might explain their results. Like in these studies, the increased blood flow in the conglomerated nodule might have been responsible for our results. Although a small number of cases showed ill-defined margins with conglomeration in our study, such nodule-related findings could predict treatment efficacy. To our knowledge, we are the first to identify nodule margin as a predictive factor of treatment efficacy. Therefore, we believe that this is an important finding. 
Our study had several limitations. First, this study had a retrospective design with a small sample size and short-term followup periods. For this reason, we found that the nodule margin was not significantly correlated with VRR. However, the current study is only preliminary research in preparation for a future prospective study that we are planning, based on the current study, but with a larger patient population. Our next challenge will be to collect sufficient evidence to confirm the hypotheses. Second, symptomatic and cosmetic scores were not evaluated in this study. However, these clinical complaints are correlated with volume reduction of the nodule according to previous studies. Baek et al. [8] have described a volume reduction ratio of $79 \%$ at 6 -months after $\mathrm{RF}$ ablation, which is similar to the findings we obtained at the 1-year follow-up. In their study, both symptomatic and cosmetic scores were better than those in the control group. Concurrently, among the patients in our study, there were no complaints associated with cosmetic problems in the follow-up period.

In conclusion, RF ablation was effective in decreasing the volume of benign thyroid nodules without complications. Internal factors such as the margin of the nodule can be helpful in predicting therapeutic success. Clinicians should pay particular attention to thyroid nodules with ill-defined margins during RF ablation.

ORCID: Hye Shin Ahn: http://orcid.org/0000-0001-7260-7467; Soo Jin Kim: http:// orcid.org/0000-0001-8233-1388; Sung Hee Park: http://orcid.org/0000-0003-1244703X; Mirinae Seo: http://orcid.org/0000-0002-8989-9504

\section{Conflict of Interest}

No potential conflict of interest relevant to this article was reported.

\section{References}

1. Gazelle GS, Goldberg SN, Solbiati L, Livraghi T. Tumor ablation with radio-frequency energy. Radiology 2000;217:633-646.

2. Dupuy DE, Goldberg SN. Image-guided radiofrequency tumor ablation: challenges and opportunities: part II. J Vasc Interv Radiol 2001;12:1135-1148.

3. McGhana JP, Dodd GD 3rd. Radiofrequency ablation of the liver: current status. AJR Am J Roentgenol 2001;176:3-16.

4. Kim YS, Rhim H, Tae K, Park DW, Kim ST. Radiofrequency ablation of benign cold thyroid nodules: initial clinical experience. Thyroid 2006;16:361-367.

5. Jeong WK, Baek JH, Rhim H, Kim YS, Kwak MS, Jeong HJ, et al. Radiofrequency ablation of benign thyroid nodules: safety and imaging follow-up in 236 patients. Eur Radiol 2008;18:1244-1250.

6. Deandrea M, Limone P, Basso E, Mormile A, Ragazzoni F, Gamarra $E$, et al. US-guided percutaneous radiofrequency thermal ablation for the treatment of solid benign hyperfunctioning or compressive thyroid nodules. Ultrasound Med Biol 2008;34:784-791.

7. Baek JH, Moon WJ, Kim YS, Lee JH, Lee D. Radiofrequency ablation for the treatment of autonomously functioning thyroid nodules. World J Surg 2009;33:1971-1977.

8. Baek JH, Kim YS, Lee D, Huh JY, Lee JH. Benign predominantly solid thyroid nodules: prospective study of efficacy of sonographically guided radiofrequency ablation versus control condition. AJR Am J Roentgenol 2010;194:1137-1142.

9. Lee JH, Kim YS, Lee D, Choi H, Yoo H, Baek JH. Radiofrequency ablation (RFA) of benign thyroid nodules in patients with incompletely resolved clinical problems after ethanol ablation (EA). World J Surg 2010;34:1488-1493.

10. Spiezia S, Garberoglio R, Milone F, Ramundo V, Caiazzo C, Assanti $A P$, et al. Thyroid nodules and related symptoms are stably controlled two years after radiofrequency thermal ablation. Thyroid 2009;19:219-225.

11. Lim HK, Lee JH, Ha EJ, Sung JY, Kim JK, Baek JH. Radiofrequency ablation of benign non-functioning thyroid nodules: 4-year followup results for 111 patients. Eur Radiol 2013;23:1044-1049.

12. Hong JM, Baek JH, Choi YJ, Lee JH, Lim HK, Shong YK, et al. Radiofrequency ablation is a thyroid function-preserving treatment for patients with bilateral benign thyroid nodules. J Vasc Interv Radiol 2015;26:55-61.

13. Sung JY, Baek JH, Jung SL, Kim JH, Kim KS, Lee D, et al. Radiofrequency ablation for autonomously functioning thyroid nodules: a multicenter study. Thyroid 2015;25:112-117.

14. Baek JH, Lee JH, Sung JY, Bae JI, Kim KT, Sim J, et al. Complications encountered in the treatment of benign thyroid nodules with USguided radiofrequency ablation: a multicenter study. Radiology 2012;262:335-342.

15. Na DG, Lee JH, Jung SL, Kim JH, Sung JY, Shin JH, et al. Radiofrequency ablation of benign thyroid nodules and recurrent thyroid cancers: consensus statement and recommendations. Korean J Radiol 2012;13:117-125.

16. Lee YJ, Kim DW, Jung SJ. Comparison of sample adequacy, painscale ratings, and complications associated with ultrasound-guided fine-needle aspiration of thyroid nodules between two radiologists with different levels of experience. Endocrine 2013;44:696-701.

17. Russ $G$. Risk stratification of thyroid nodules on ultrasonography with the French TI-RADS: description and reflections. Ultrasonography 2016;35:25-38.

18. Lee SJ, Jung SL, Kim BS, Ahn KJ, Choi HS, Lim DJ, et al. Radiofrequency ablation to treat loco-regional recurrence of well-differentiated thyroid carcinoma. Korean J Radiol 2014;15:817-826.

19. Ha EJ, Baek JH, Lee JH. Ultrasonography-based thyroidal and perithyroidal anatomy and its clinical significance. Korean J Radiol 2015;16:749-766.

20. Moon WJ, Jung SL, Lee JH, Na DG, Baek JH, Lee YH, et al. Benign and malignant thyroid nodules: US differentiation: multicenter 
retrospective study. Radiology 2008;247:762-770.

21. Moon WJ, Baek JH, Jung SL, Kim DW, Kim EK, Kim JY, et al. Ultrasonography and the ultrasound-based management of thyroid nodules: consensus statement and recommendations. Korean J Radiol 2011:12:1-14.

22. Hoang JK, Lee WK, Lee M, Johnson D, Farrell S. US features of thyroid malignancy: pearls and pitfalls. Radiographics 2007;27:847860.

23. Bernardi S, Dobrinja C, Fabris B, Bazzocchi G, Sabato N, Ulcigrai V, et al. Radiofrequency ablation compared to surgery for the treatment of benign thyroid nodules. Int J Endocrinol 2014;2014:934595.
24. Ha EJ, Baek JH, Lee JH. Moving-shot versus fixed electrode techniques for radiofrequency ablation: comparison in an ex-vivo bovine liver tissue model. Korean J Radiol 2014;15:836-843.

25. Baek JH, Lee JH, Valcavi R, Pacella CM, Rhim H, Na DG. Thermal ablation for benign thyroid nodules: radiofrequency and laser. Korean J Radiol 2011;12:525-540.

26. Gambelunghe G, Bini V, Stefanetti E, Colella R, Monacelli M, Avenia $N$, et al. Thyroid nodule morphology affects the efficacy of ultrasound-guided interstitial laser ablation: a nested case-control study. Int J Hyperthermia 2014;30:486-489. 